\title{
Primary osteoarthritis of the elbow
}

\author{
MICHAEL DOHERTY ${ }^{1}$ AND BRYAN PRESTON \\ From the ${ }^{1}$ Rheumatology Unit, City Hospital; and the ${ }^{2}$ Department of Radiology, Queen's Medical Centre, \\ Nottingham
}

SUMmaRY Sixteen patients (14 male, two female; mean age 61, range 49-75 years) with elbow osteoarthritis (OA) unassociated with nodal or crystal related $\mathrm{OA}$ were studied. None had received obvious trauma. The dominant elbow was affected in 14 , the other in 12 (mean symptom onset in these 26 elbows 53 years (range 31-63), mean symptom duration 7 years (range 1-20)). Joint fluids (six patients) were non-inflammatory: biopsy (two) showed non-specific synovitis. Radiographic changes occurred in humeroulnar $(25 / 26,96 \%)$, humeroradial $(100 \%)$, and radioulnar $(22 / 26 ; 85 \%)$ compartments: uniform narrowing with hypertrophic changes predominated and osseous bodies were common $(18 / 26,69 \%)$. Thirteen had OA elsewhere, notably 2nd/3rd metacarpophalangeal joints $(10 / 16,62 \%)$, knees $(6 / 16,38 \%)$, and hips $(5 / 16,31 \%)$. A good clinical outcome was observed in $22 / 26$ elbows. In our experience symptomatic 'primary' OA of the elbow particularly affects middle aged men, commonly associates with metacarpophalangeal OA ('Missouri metacarpal syndrome'), and has a favourable outcome. Contrary to previous reports a major role for trauma is difficult to substantiate.

Although osteoarthritis (OA) of the elbow occasionally occurs in the setting of nodal generalised OA and pyrophosphate arthropathy,${ }^{1-3}$ involvement at this site, particularly the humeroulnar compartment, is otherwise considered uncommon. ${ }^{45}$ When it does occur it is usually reported as 'secondary' to mechanically derived occupational or traumatic factors-for example, in pneumatic drillers, ${ }^{6}$ chipping and grinder operators, ${ }^{7}$ foundry workers, ${ }^{8}$ handball players, ${ }^{9}$ baseball pitchers. ${ }^{10}$ We studied 16 consecutive patients referred with symptomatic elbow OA unassociated with nodal or crystal related OA. Findings in this series are presented and discussed, particularly in relation to clinical and radiographic features, outcome, predisposing factors, and association with $\mathrm{OA}$ at other sites.

\section{Patients and methods}

Sixteen patients (14 male, two female; mean age 61 , range $49-75$ years) were culled from 225 patients (7\%) referred to a rheumatology clinic over a three year period with non-nodal 'uncomplicated' large joint OA - that is, no Heberden's/Bouchard's nodes,

Accepted for publication 17 January 1989.

Correspondence to Dr Michael Doherty, Rheumatology Unit, City Hospital, Nottingham NG5 1PB. polyarticular interphalangeal $\mathrm{OA}$, chondrocalcinosis, or synovial fluid calcium pyrophosphate dihydrate crystals.

Each underwent a full history and examination, with specific inquiry for trauma or occupational/ recreational factors likely to affect elbows. Plain radiographs were taken of elbows, hands, feet, knees, and pelvis (and other clinically involved joints). Laboratory investigations included calcium, alkaline phosphatase, ferritin, magnesium, thyroid function, creatinine, uric acid, rheumatoid and antinuclear factors. Joints with overt synovitis were aspirated and fluids examined for cells, birefringent crystals (polarised light microscopy), calcium staining particles (alizarin red $^{11}$ ), and complement activation (C3dg). ${ }^{12}$ Synovial biopsy was undertaken in two patients with persistent synovitis, and routine histology performed.

\section{Results}

Osteoarthritis affected both elbows in 10 patients, the dominant side alone in four, and the nondominant alone in two. The mean age of symptom onset in these 26 elbows was 53 (range 31-63) years, with mean symptom duration of 7 (range 1-20) years. In all 10 patients with bilateral OA the dominant side was affected first (mean age onset 50 , 
range $31-60 v 55$, range $45-63$ years) and showed longer symptom duration (mean 8, range 2-20v6, range $1-15$ years). No patient had antecedent trauma to the elbow, and only three (men with bilateral OA) had 'manual' occupations (builder, plumber, taxi driver): the plumber was a keen

Table 1 Compartmental distribution of radiographic abnormality in the 26 affected elbows

\begin{tabular}{llll}
\hline $\begin{array}{l}\text { Radiographic } \\
\text { findings }\end{array}$ & \multicolumn{2}{l}{ Compartment } & \\
\cline { 2 - 4 } & $\begin{array}{l}\text { Humeroulnar } \\
\text { No }(\%)\end{array}$ & $\begin{array}{l}\text { Humeroradial } \\
\text { No }(\%)\end{array}$ & $\begin{array}{l}\text { Radioulnar } \\
\text { No }(\%)\end{array}$ \\
\hline Abnormality & $25(96)$ & $26(100)$ & $22(85)$ \\
Narrowing & $18(69)$ & $\begin{array}{l}20(77) \\
\text { (uniform }\end{array}$ & $3(12)$ \\
& $\begin{array}{l}\text { (uniform } \\
\text { mainly, }\end{array}$ & $\begin{array}{l}\text { mainly, } \\
3(12 \%)\end{array}$ & \\
& $4(15 \%)$ & eccentric) & \\
Osteophyte & $23(88)$ & $23(88)$ & $20(77)$ \\
$\begin{array}{l}\text { Cysts } \\
\text { 'Loose' bodies }\end{array}$ & $5(19)$ & $5(19)$ & - \\
Marked bone & $10(38)$ & $11(42)$ & - \\
attrition & $1(4)$ & $2(8)$ & - \\
\hline
\end{tabular}

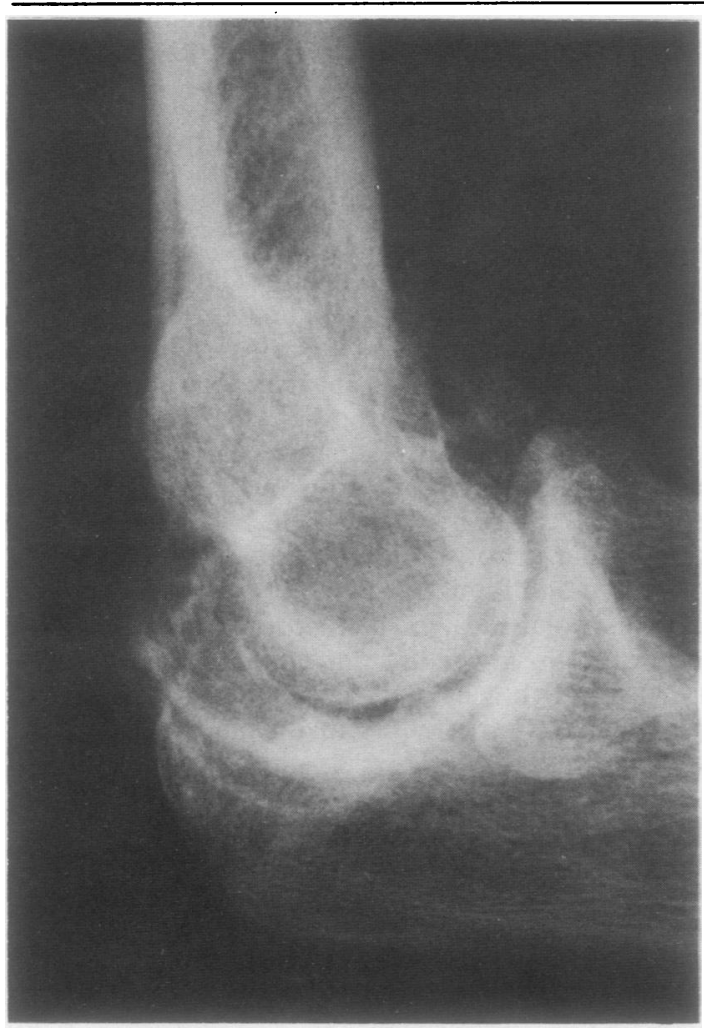

Fig. 1 Lateral elbow radiograph of a 60 year old man showing large anterior 'loose' bodies associated with osteoarthritis.

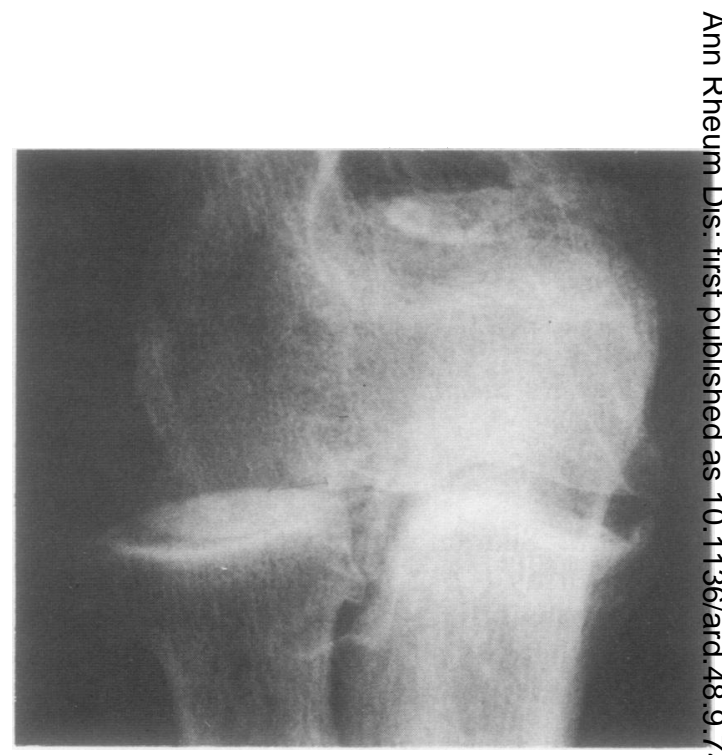

Fig. 2 Anteroposterior elbow radiograph of a 59 year old $\stackrel{\omega}{\omega}$ man showing eccentric humeroradial joint space loss.

amateur cricketer, but no other recreational activitie $\frac{\mathbb{D}}{\frac{C}{0}}$ could be incriminated. Only four gave a famil: history of OA (nodal generalised OA in two, kneeథ in four, hips in two): examination of relatives past not undertaken.

Pain on use was the principal symptom (1000 early morning and inactivity stiffness were commang and marked in six patients (six elbows). All $2 \%$ involved elbows showed restricted humeroulna. movement (fixed flexion, reduced flexion); decrease in supination/pronation was present in only two? Crepitus was common in the humeroulnar $(88 \% \vec{\Phi}$

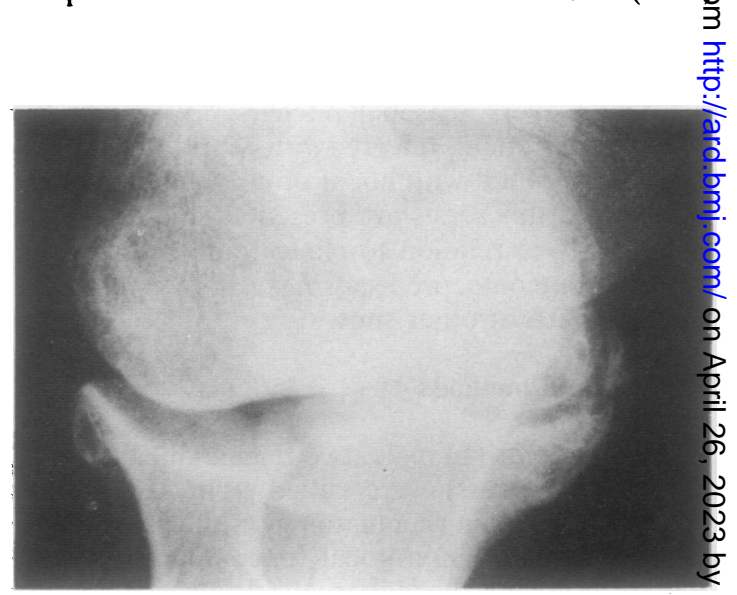

Fig. 3 Anteroposterior elbow radiograph of a 64 year old $\stackrel{0}{=}$ man showing marked attrition with apparent increase in joint space in the humeroradial compartment, and concentric narrowing and osteophytosis in the humeroulnar joint. 


\section{SYMPTOMS RADIOGRAPHS}

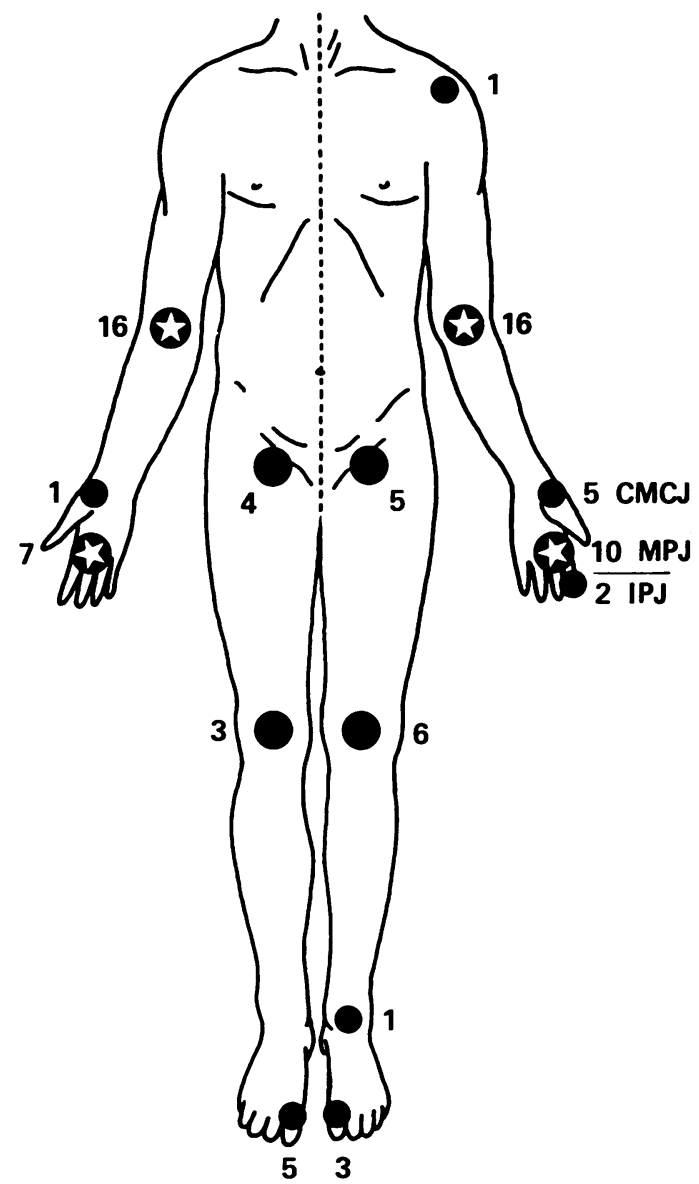

Fig. 4 Occurrence of symptomatic (left) and radiographic (right) $O A$ at other sites in the 16 patients (represented as numbers of patients). CMCJ=carpometacarpal joint; $M P J=$ metacarpophalangeal joint; $I P J=$ interphalangeal joint.

and two radial $(77 \%)$ compartments. Clinical synovitis (stress pain, warmth, fluid, and soft tissue swelling) was evident in the six patients with inflammatory symptoms: synovial fluids (six) obtained from five of these were 'non-inflammatory' with high viscosity, low cell counts (predominantly mononuclear), no birefringent crystals, only weak alizarin red positivity (three), and no increase of $\mathrm{C} 3 \mathrm{dg}$. Biopsy specimens (two cases) showed only modest synovial hyperplasia, no inflammatory cell infiltrate or prominence of macrophages, and no crystals or calcific particles. Haematological and biochemical investigations showed no significant abnormality in any patient.
Radiographic abnormalities were noted to varying extent in all elbow compartments (Table 1). Osteophytosis with hypertrophic remodelling was common and usually most florid in the humeroulnar compartment: associated 'loose' osseous bodies were frequent both anteriorly and posteriorly $(18 / 26(69 \%)$ of elbows; Fig. 1). Decrease in interosseous distance in humeroulnar and humeroradial compartments was predominantly uniform but occasionally eccentric (Fig. 2); marked attrition of bone was unusual but associated with apparent widening of joint space in two cases (Fig. 3). Cysts were not a prominent feature. Entheseal new bone formation in triceps tendon (olecranon spur) occurred in $4 / 26(15 \%)$ elbows.

Three patients had isolated elbow OA but 13 $(81 \%)$ had clinical or radiographic evidence, or both, of OA elsewhere (10 symptomatic; Fig. 4). Second and third metacarpophalangeal (MCP) joints were most commonly involved (10 patients; Fig. 5), followed by knees (six; three with patellofemoral OA only), hips (five: four superior, one medial), first carpometacarpophalangeal joints (five), and first metatarsophalangeal joints (three). Two had radiographic changes of mild interphalangeal $\mathrm{OA}$ ( $<3$ rays each hand), but none had nodal generalised OA or chondrocalcinosis (in accord with inclusion criteria). Non-inflammatory joint fluids were obtained in $4 / 6$ patients with knee OA; none contained calcium pyrophosphate dihydrate crystals.

Treatments given for symptomatic elbows varied but included intra-articular steroid injection (one to three occasions in six patients), analgesic and nonsteroidal anti-inflammatory drugs, and physiotherapy; no patient received surgery. At the time of writing (one year after the three year recruitment period-that is, 0-16 year retrospective, 1-4 year prospective study) the clinical outcome for involved elbows has been favourable. Twenty two elbows have shown loss or amelioration of symptoms, three (dominant) have persisted unchanged, and only one (non-dominant) has shown symptom worsening. Although two of the manual workers lost time from work, all patients have continued employment and experienced only relatively minor, usually episodic, difficulties with daily activities. The associated MCP joint $\mathrm{OA}$ has uniformly shown good symptomatic and functional outcome.

\section{Discussion}

The elbow is generally considered a protected site for development of OA. ${ }^{45}$ Pathologically the humeroradial joint may show chondromalacic and age related change, but the humeroulnar compart- 


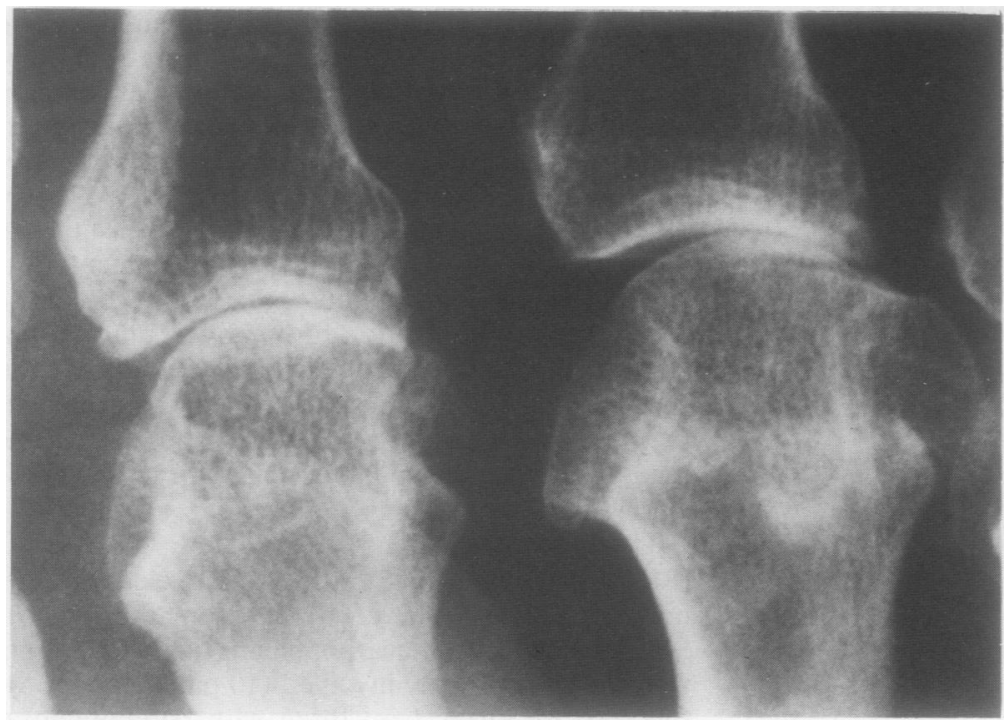

Fig. 5 Anteroposterior hand radiograph of a 58 year old man showing eccentric joint space loss, $\rightarrow$ sclerosis, and osteophyte of second and third metacarpophalangeal joints.

ment appears resistant to 'degeneration', ${ }^{4}$ this low frequency of involvement possibly being influenced by racial or ethnic factors. ${ }^{314}$ 'Primary' OA of the elbow is recognised to occur in nodal generalised $\mathrm{OA}$ and pyrophosphate arthropathy, ${ }^{1-3}$ but even in these subsets involvement, which predominates in women, remains uncommon. ${ }^{1-3}$ Most published series are restricted to men with elbow OA apparently secondary to repetitive occupational or recreational trauma, ${ }^{6-10}$ and such reports emphasise mechanical factors alone in pathogenesis. Reasons for relative immunity from $\mathrm{OA}$ at the elbow remain unclear, though hypotheses to explain uneven distribution of $\mathrm{OA}$ include differing mechanical forces ${ }^{15}$ and effects on joint design resulting from varying rapidity of evolutionary change. ${ }^{16}$ For the humeroulnar joint mechanical benefits of a hinge movement have particularly been emphasised. ${ }^{4}$

In the present series we studied patients referred to hospital with symptomatic elbow OA showing no evidence of nodal generalised OA or pyrophosphate arthropathy and unselected in terms of occupational predisposition. Most were middle aged men, in whom overt occupational or recreational trauma could not be incriminated. Loose bodies were common, but none had associated osteochondritis. ${ }^{17}$ Metabolic screening was also negative, and such cases are therefore regarded as primary. Usage, however, may be an additional determining factor, ${ }^{18} 19$ as suggested by earlier involvement and longer symptom duration on the dominant side. Male predominance and good clinical outcome concurs with a French retrospective study in which $78 \%$ of cases were considered to be related to occupation. Clinically significant ulnar nerve entrapment, $\mathbb{Q}$ common complication $(16 \%)$ in the French serfes was not observed in our study. If primary elbow is a relatively benign, often asymptomatic ${ }^{60}$ condig tion it may be more common than is gener?als supposed, and uncontrolled surveys in an industria setting ${ }^{6}{ }^{8}$ could be misleading in terms of relevarif predisposing factors.

Previous reports of elbow OA have not commente\& on associated involvement at other sites, but in ouक series it was striking that $10 / 14(71 \%)$ of men ha MCP joint OA. As with the elbow, MCP joints are often considered an uncommon site for $\mathrm{OA},{ }^{5}$ though their involvement is recognised in noda generalised $\mathrm{OA}^{22}$ and pyrophosphate arthro pathy, ${ }^{323}$ particularly in association with haemo chromatosis. ${ }^{24}$ Metacarpophalangeal joint OA in men has recently been emphasised in relation to heavy manual work ('Missouri metacarpal synt drome, ${ }^{, 21}$ ), though it is noteworthy that all seve cases described had coexistent nodal generalise $\mathrm{OA}$ as a predisposing factor. Our patients are of interest in having predominantly isolated MCP joinf involvement in the hand in the absence of nodăb generalised $\mathrm{OA}$, obvious trauma, or metaboli predisposition. All were reviewed at an age whefi nodal generalised $\mathrm{OA}$ might have been expected to have developed, though other characteristic joints 6 for example, first carpometacarpal joints, wer additionally involved in some. It is tempting to speculate that predominant elbow and MCP join involvement may reflect a male pattern of generalise 
OA associated with good outcome at principally involved sites. Further studies are required to explain development and distribution of OA within individuals: although usage and trauma may be cofactors, constitutional determinants also appear important. ${ }^{19}$

We wish to thank the Arthritis and Rheumatism Council for continuing support, and Caroline Bloomfield for secretarial assistance.

\section{References}

1 Huskisson E C, Dieppe P A, Tucker A K, Cannell B. Another look at osteoarthritis. Ann Rheum Dis 1979; 38: 423-8.

2 Dieppe P A, Alexander G M, Jones $\mathrm{H}$, et al. Pyrophosphatc arthropathy: a clinical and radiological study of 105 cases. Ann Rheum Dis 1982; 41: 371-6.

3 Doherty M. Pyrophosphate arthropathy-a clinical study. Cambridge University, 1987. (MD thesis.)

4 Goodfellow J W, Bullough P G. The pattern of ageing of the articular cartilage of the elbow joint. J Bone Joint Surg [Br] 1967; 49: 175-81.

5 Resnick D, Niwayama G. Degenerative disease of extra-spinal locations. In: Resnick D, Niwayama G, eds. Diagnosis of bone and joint disorders. Philadelphia: Saunders, 1981: 1270-367.

6 Ravault P P, Roche L, Maitrepierre J, Chaudy J (Lyon). Les ostéo-arthropathies des marteaux pneumatiques. Rev Rhum Mal Osteoartic 1963; 30: 724-33.

7 Bovenzi M, Fiorito A, Volpe C. Bone and joint disorders in the upper extremities of chipping and grinding operators. Int Arch Occup Environ Health 1987; 59: 189-98.

8 Mintz G, Fraga A. Severe osteoarthritis of the elbow in foundry workers. Arch Environ Health 1973; 27: 78-80.

9 Hellmann D B, Helms C A, Genant H K. Chronic repetitive trauma: a cause of atypical degenerative joint disease. Skeletal Radiol 1983; 10: 236-42.

10 Bennett G E. Shoulder and elbow lesions of the professional baseball pitcher. JAMA 1941; 117: 510-5.
11 Paul H, Reginato A J, Schumacher H R. Auzann red S staining as a screening test to detect calcium compounds in synovial fluid. Arthritis Rheum 1983; 26: 191-200.

12 Doherty M, Richards N, Hornby J, Powell R. Relation between synovial fluid C3 degradation products and local joint inflammation in rheumatoid arthritis, osteoarthritis and crystal associated arthropathy. Ann Rheum Dis 1988; 47: 190-7.

13 Ortner D J. Description and classification of degenerative bone changes in the distal joint surfaces of the humerus. Am J Phys Anthropol 1968; 28: 139-56.

14 Jurmain R D. Stress and the etiology of osteoarthritis. Am J Phys Anthropol 1977; 46: 353-66.

15 Radin E L. Aetiology of osteoarthritis. Clin Rheum Dis 1976: $509-22$.

16 Hutton C W. Generalised osteoarthritis: An evolutionary problem? Lancet 1987; i: 1463-5.

17 Bell M S. Loose bodies in the elbow. Br J Surg 1975; 62: 921-4.

18 Hadler N M, Gilings D B, I nbus H R, et al. Hand structl. e ana function in an industrial setting. Influence of three patterns of stereotyped, repetitive usage. Arthritis Rheum 1977; 20: 1019-25.

19 Doherty M, Watt I, Dieppe P A. Influence of primary generalised osteoarthritis on development of secondary osteoarthritis. Lancet 1983; ii: 8-11.

20 Ruelle M, Dubois J L, Debeuckelaere M, Raynal L. Introduction a l'étude du coude. Journale Belge de Rhumatologie et de Medecine Physique 1965; 20: 161-7.

21 Williams W V, Cope R, Gaunt W D, et al. Metacarpophalangeal arthropathy associated with manual labor (Missouri metacarpal syndrome). Arthritis Rheum 1987; 30: 1362-71.

22 Martel W, Snarr J W, Horn J R. The metacarpophalangeal joints in interphalangeal osteoarthritis. Diagnostic Radiology 1973; 108: 1-7.

23 Martel W, Champion C K, Thompson G R, Carter T L. A roentgenologically distinctive arthropathy in some patients with the pseudogout syndrome. American Journal of Roentgenology, Radium Therapy and Nuclear Medicine 1970; 109: 587-605.

24 Adamson T C, Resnik C S, Guerra J, Vint V C, Wiesman M H, Resnick D. Hand and wrist arthropathies of hemochromatosis and calcium pyrophosphate deposition disease: distinct radiographic features. Radiology 1983; 147: 377-81. 